\title{
Exploring Ethnocentrism in Business Courses and Businesses
}

\author{
Dianne Weinstein ${ }^{1}$ \\ ${ }^{1}$ Cobalt Solutions, Inc. Rockville Centre, New York, U.S.A. \\ Correspondence: Dianne Weinstein, Cobalt Solutions, Inc. Rockville Centre, New York, U.S.A. Tel: \\ 1-516-763-3178. E-mail: diannew@cobalt-solutions.com
}

Received: July 20, 2013

Accepted: September 6, 2013

Online Published: September 10, 2013

doi:10.5430/bmr.v2n3p120

URL: http://dx.doi.org/10.5430/bmr.v2n3p120

\begin{abstract}
Business students and practitioners are often unfamiliar with the underlying rationale for ethnocentrism and the resulting consequences of ethnocentric behavior in the workplace. The author presents a compelling exercise that makes the topic of ethnocentrism personally relevant to both students and practitioners alike. Through experiential activities, brief lectures, and presentations, participants learn about the psychological factors creating ethnocentric tendencies, identify examples of ethnocentric issues, and learn how ethnocentric tendencies affect employee behaviors in the classroom and at work. The Exercise helps participants recognize the potential for ethnocentrism in themselves and others, enhances inter-cultural sensitivity, and elevates global awareness. Step-by-step detailed teaching instructions and support tools are provided for easy Exercise implementation within ground, distance learning, and hybrid courses or business settings.
\end{abstract}

Keywords: Ethnocentrism, Communication, Conflict management, Cross-cultural management, Experiential learning, Organizational behavior, Organizational culture

If someone were to put a proposition before men bidding them choose, after examination, the best customs in the world, each nation would certainly select its own." -- Herodotus, Greek Historian

\section{Introduction}

Ethnocentrism has been defined as "an evaluative bias in favor of one's own group (in-group) and the perception of out-groups (all other groups) as being inferior" (Templer, 2010). Sumner (1906), the originator of the term, described ethnocentrism as the view of things in which one's own group is the center of everything, and all others are scaled and rated with reference to it...Each group nourishes its own pride and vanity, boasts itself superior, exalts its own divinities and looks with contempt on outsiders (p. 13).

The purpose of this paper is to describe an approach to successfully explore ethnocentrism with the business classroom or work setting. A theoretical introduction is first provided as a backdrop for developing this pedagogy including: the rationale for examining ethnocentrism in business courses and workplaces, psychological theories purported to explain the origins of ethnocentrism, and the teaching framework utilized. Steps to deliver each activity are described, together with support tools for application (in ground and online learning environments), and participant feedback on topical issues.

\section{Background}

As Sumner (1906) relates, people judge other groups in relationship to the values and standards of their own group. Put another way, people see the world through the lens of their own culture. This ethnocentric focus limits and distorts peoples' views of the world, often leading them to make false assumptions about cultural differences and other groups.

As a result, ethnocentric thinking can disrupt or obstruct business activities. For example, ethnocentrism can hinder rational strategic planning because it distorts key aspects of strategic thinking (Booth, 1979). Imagine a United States $\mathrm{CEO}$ who will not entertain a merger with a foreign organization because this company is headquartered in a country that the CEO believes is intelligently inferior to Americans.

Ethnocentric tendencies may also create relationship conflicts when managers promote their own country's value-based management systems within other countries and ignore the different local country customs and norms 
(Begley \& Boyd, 2003). As an example, Thomas and Hill (1999) relate that when one organization was "going international," implementing a corporate identity strategy backfired when the strategy reflected ethnocentric views. In another example, Wiarda (1985) identifies ethnocentrism as a critical factor that undermined the success of various United States foreign policies.

Unfortunately, the issue of ethnocentrism continues to be quite pervasive in the world today (Bizumic, Duckitt, Popadic, Dru, \& Krauss, 2009, p. 871; Ogretir \& Ozcelik, 2008). Consequently, it is not unlikely that business students or practitioners will be involved in ethnocentric incidents at work during their careers. Although topics related to ethnocentrism (e.g. diversity, individual differences, cultural differences and business ethics) are commonly discussed at work and at school, the issue of "ethnocentrism" is not typically identified as a key topic for workplace or classroom discussion.

In an attempt to understand this deficiency in ethnocentrism education, I informally surveyed peer instructors to gain some perspective on the issue-at-hand. Some surveyed instructors indicated that they refrained from teaching ethnocentrism as they did not know much about the topic. Other instructors did not deem the topic to be very important. One instructor related, "after all, the topic only receives a one or two lines in most management textbooks." Some academics with little or no business experience were challenged to translate ethnocentric theory into real-world business examples for application in their courses. Other instructors believed that ethnocentrism was a "hot" topic too sensitive for valuable discussion in the classroom. ("Once you start talking about personal ethnocentric tendencies you're bound to upset students.") Alternatively, various instructors preferred to focus on the positive aspects of cultural sensitivity rather than address the potential negative issues associated with ethnocentrism. In addition, a few very honest souls indicated that they themselves were ethnocentric and did not teach the topic because their own ethnocentric views might leak into classroom discussions.

According to Nehrt (1993, p. 81), "it is the responsibility of education to prepare people for the world in which they will be living." Consequently, despite the above-noted reasons for glossing over the ethnocentrism issue, business students and practitioners need to understand how ethnocentrism can impact their career success or the success of their employers. By not analyzing ethnocentric beliefs in the classroom, instructors infer that such beliefs are acceptable or allowable as they are part of human nature (Postman, 1995). Actually, various theorists purport that ethnocentrism is a part of human nature (Lynn, 1976; Mihalyi, 1984; Rushton, 1989). Most people are ethnocentric at one point or another as people best relate to their own cultures, -- yet people are generally unaware of their own ethnocentric proclivities (Barger, 2008; Cunningham, Nezlek, \& Banaji, 2004). Self-awareness of one's ethnocentric tendencies can provide students with the knowledge and the means to address ethnocentric issues so as not to hinder their workplace success. Recognizing ethnocentrism in others may also help students support their colleagues in their efforts to work through this issue, as well.

Various research studies reinforce the importance of emphasizing ethnocentrism education in the business classroom. For example, a 2011 study conducted by Tomkiewisc, Bass, and Gribble evaluated ethnocentrism among college business students in a public United States university. Students completed an index instrument where students described managers from various countries. Study findings demonstrated significant differences among the students' perceptions of the cultures under study, suggesting that dysfunctional conflicts may occur based on incorrect cultural assumptions. These researchers indicated that ethnocentrism is a potential issue for today's students in spite of significant educational efforts to advance multiculturalism within business schools. Furthermore, student ethnocentrism is a potential barrier to students' careers as they tackle the globalization of the job market.

In another study, Grant and Wren (1993) indicated that student ethnocentrism was associated with negative attitudes toward the importance and willingness to enroll in foreign language, international business, and business ethics courses. Many United States universities develop diversity programs, multicultural programs, exchange programs, and global business programs with the goal of promoting internationalization within higher education. However, well-known educator, Roger W. Bowen (2000) indicates that student ethnocentrism is one of the many barriers blocking the success of internationalizing American institutions. Moreover, researcher, Thomas Scott (1998) relates that "it is imperative that we combat ethnocentric attitudes and the behaviors that emerge from them if our students are to function harmoniously in an increasingly interdependent world."

Thus, with the expansion of business globalization and higher institution's push to internalize college campuses, the need to educate students on ethnocentrism cannot be understated. Bush and Bush (1998) indicated that business practitioners want to see students graduate with more specific skills and characteristics that relate to actual job experience. Indeed, if college students are to be successful in today's multicultural, business world, they need to understand ethnocentrism and cultivate "a culturally sensitive frame of reference and mode of operation" (Rosado, 1994, p.1). Johan van der Dennen (1986) suggested that to demystify the complexity of ethnocentric tendencies, instructors should integrate detailed examination and real-life illustrations of ethnocentrism in their classrooms. This 
paper now provides a brief overview on the psychology of ethnocentric tendencies as a starting point to understand and address the above comments and suggestions.

\subsection{The Psychology of Ethnocentric Tendencies}

Various theories have been developed in an attempt to explain the origins of ethnocentrism. Some of the key theories are summarized below as background for instructors teaching ethnocentric theory.

So why are people ethnocentric? One hypothesis is that ethnocentric tendencies of parents are taught to their children just as attitudes about religion or politics are taught (Mosher \& Scodel, 1960). Children hear their parents discussing different groups of people and retain information that forms the basis for ethnocentric views. A second hypothesis relates to the childrearing practices of austere parents. The Authoritarian Personality Theory (Adorno, Frenkel-Brunswik, Levinson, \& Sanford, 1950) suggests that authoritarian personalities originate because children of strict parents were not able to express hostility towards their parents. Instead these children learned to displace their hostility onto weaker target groups. Consequently, individuals with authoritarian personalities categorize individuals into "us" and "them" groups and view their own individual group as superior.

The Belief Congruence Theory (Rokeach \& Rothman, 1965) suggests that that the most significant determinant of an individual's view toward another person is the congruence between the two people's beliefs, attitudes and values. Moreover, the Similarity-Attraction Theory (Brynes, 1971) proposes that we are attracted to people who are like ourselves because these people validate our beliefs about ourselves. Where there is high similarity, reciprocal attraction is thought to occur. Alternatively, dissimilarity encourages a negative orientation toward the other party. The Realistic Conflict Theory (Sherif, Harvey, White, Hood, \& Sherif, 1961) suggests that hostility between two groups occurs due to real or perceived conflicting objectives which create competition between the two groups. Feelings of resentment arise because each group envisions that only one group will win the competition and the other group will lose. Consequently, negative stereotypes about, and hostility toward, the other group (the out-group) develops.

The Frustration-Aggression Theory (Berkowitz, 1972; Dollard, Doob, Miller, Mowrer, \& Sears, 1939) suggests that anger arises when individuals believe that they are not being fairly treated. This anger results in intergroup conflict which can then escalate into ethnocentrism (Grant \& Brown, 1995). According to the related Scapegoat Theory, people may be prejudice toward a group and use the group they dislike as the target for their anger as a way to vent their frustrations with various issues. For example, the Scapegoat Theory suggests that the Germans viewed Jewish people as scapegoats for German country problems. A concentration of anger built up amongst the German population which resulted in a massive ethnocentric hatred of Jewish people.

The Social Identity Theory (Tajfel \& Turner, 1985) suggests that individuals seek out group membership to validate their own self esteem. However membership in the group is not enough to confirm self esteem. Instead, individuals need to feel that they are in the "correct" group, which produces the need to make favorable distinctions between the in-group versus the out-group. Positive comparisons of one's group to other groups make individuals feel that their group is superior. Alternatively, the Relative Deprivation Theory (Stouffer, Suchman, DeVinney, Star, \& Williams, 1949) refers to the discontent people feel when they compare their positions to those of similarly situated people and realize that they have less than their peers. It is a condition that is measured by comparing one group's situation to the situations of those who are more advantaged.

Additionally, Barger (2008) suggests that ethnocentrism can be defined as "making false assumptions about others' ways based on one's own limited experience." Barger relates that

what we have already experienced is the basis for our "reality", what we expect. It is normal to assume it is the "natural" basis of reality... because our own ways work for us. Our perceptions of colors, our time frames, our values on industriousness, our social roles, our beliefs about Life and the Universe, and all our other ways help us organize life experience and provide important meanings and functions as we move through daily and life span activities. Therefore, our limited experiences we have already had are the basis for interpreting new experiences, in this case, others' behavior.

Put another way, people automatically view another group based on their own individual frames of reference which results in denouncing the other group as abnormal. This idea brings to mind a quote by Mark Twain: "But we are all that way: when we know a thing we have only scorn for other people who don't happen to know it "(1896.)." As such, individuals will unconsciously deride what they do not understand and affirm their own beliefs as superior.

Consequently, behaviors linked to ethnocentrism often include poor collaborative relations with other individuals. Alternatively, ethnocentric behaviors can also include preferential treatment within groups (LeVine \& Campbell, 1972) as evidenced by research on in-group favorable bias (Brewer, 1979; Mullen, Brown, \& Smith, 1992). For example, beneficial treatment of in-groups has been demonstrated with regards to trust and cooperation (Wit \& Kerr, 2002; Yuki, Maddux, Brewer, \& Takemura, 2005), standards of fairness (Platow, McClintock, \& Liebrand, 1990) 
and assessments of group products (Gerard \& Hoyt, 1974). Moreover, research suggests that in-group favoritism is automatically initiated when a group identity is prominent (Otten \& Moskowitz, 2000; Otten \& Wentura, 1999).

Indeed, ethnocentrism is a "universal phenomenon that is rooted deeply in most areas of inter-group relations" (Lewis, 1976). Consider that, for the most part, the above discussion focuses on a limited group of people, i.e., a number of individuals assembled together or having some unifying relationship. What if this discussion was broadened to include a societal or national culture? "The belief that a membership group or subculture is superior to all others can creep into the workplace and adversely affect the way people relate to one another" (Schermerhorn, Jr., 2010, p.76). Furthermore, business scholars, Calof and Beamish (1994), suggest that management's international business attitude is one of the most important factors influencing international business success. Consequently, astute organizational management recognizes that reducing and/or eliminating ethnocentrism enhances employees' understanding of competitive business environments (Grant \& Wren, 1993) and improves business relationships. Moreover, understanding ethnocentrism is an important topic for the business classroom. Learning about ethnocentrism enhances a student's ability to recognize and address ethnocentric issues, which promotes decision-making without distortion due to ethnocentric thinking (Grant \& Wren, 1993).

\section{Introducing the Ethnocentrism Exercise for Students}

Instructors facilitate a sequence of brief lectures, experiential activities and a writing assignment which encourage students (and/or business practitioners) to explore the topic of ethnocentrism. The Exercise was originally designed for application within ground undergraduate courses that address topics such as global business, leadership, management, organizational behavior and diversity. (Components of this Exercise have also been utilized in business settings for training initiatives that include an ethnocentrism component.) The Exercise is typically delivered as a precursor activity for higher level business topics such as cultural relativism. The three learning objectives for this Exercise are to help students (1) recognize the potential for ethnocentrism in themselves and others, (2) enhance inter-cultural sensitivity, and (3) elevate global awareness.

Table 1. Overview of the Exercise Activities

\begin{tabular}{lll}
\hline Activity & Topic & Appendix \\
\hline 1 & Globalization of Industry Trend & \\
2 & Assess the Country & A \\
3 & Define Ethnocentrism & \\
4 & Psychology of Ethnocentrism & \\
5 & The Ethnocentric Lens & B \\
6 & Assignment: Ethnocentric Movie Clips & C1 \\
7 & Research and Reflection Paper Instructions & C2 \\
& Research and Reflection Paper Instructions - & \\
& ePortfolio Version & D
\end{tabular}

A framework for the Exercise is shown in Table 1, together with the supplemental forms supporting each of the sequential activities. The Exercise may also be applied in distance learning or hybrid courses with modification. (Refer to the Exercise Variations section below for discussion of this topic.)

\subsection{Advance Preparation by the Instructor}

Preparatory steps include the following: (a) review the entire Exercise for understanding, (b) determine due dates and course credit (for institutional programs), as appropriate, (c) copy Activity handouts for distribution to participants, (d) post Activities on the institution's or organization's electronic course management system for application according to Activity timelines, (e) obtain twenty small containers (baskets, cans, envelopes, etc.) that can hold slips of paper submitted by course students, (f) create one sign for each of the 10 countries noted in Appendix A and place these signs around the course room. Near each country sign, place two containers, -- one marked "for" and the other marked "against," and (g) prepare examples of ethnocentrism for Exercise activities as deemed appropriate. 


\subsection{Exercise Activities}

Descriptions of the Exercise activities are outlined below.

Activity 1. Lead an introductory discussion on the globalization of business and the rationale for participants to learn how to succeed in the international arena. Potential topics could include: the accelerated globalization of business which creates the need for organizations to extend their business practices to countries outside of the United States and to work with people from other countries within the United States; statistics on the growth of international business; and how business practitioners are more frequently hiring students with skills and characteristics related to international work. (Instructors can provide illustrations of these points in relationship to specific course or work disciplines such as leadership, management, diversity, etc.)

Activity 2. Distribute the Assess the Country Activity (Appendix A) for completion. (Note: Instructors are encouraged to modify the countries displayed in Activity 1 to meet the needs of their individual courses and participant populations.) Read the instructions for the activity to the participants and ask participants to complete the activity. Indicate that all responses are confidential (participants should not place their names on their responses) and participants should honestly provide answers that reflect their true feelings. Also, indicate that there is no "right" or "wrong" answer to this activity.

After participants complete the activity advise participants to individually rip off any "for" and "against" answers for England, the first country listed in Appendix A. Slips of paper should be crumbled into small balls. One-by-one, participants then place the crumbled balls of paper into either the "for" or "against" containers for England, as appropriate. The same process is then repeated for each of the remaining countries on the activity list. (Having participants deposit their responses into containers immediately produces movement within the classroom, engages participants with the task, and creates an air of mystery to the activity.) Then ask participant "volunteers" to read aloud the "for" and "against" reasons why the participants wish or do not wish to interact with a specific country. The instructor (and if necessary, additional participant volunteers) notes these responses on the board.

Participants' reasons for interacting with a country can range from basic answers such as "I would like to go shopping in this country" to "the food in this country is great." However, in my experience (after delivering this Exercise many times), there will also be responses that reflect more insightful reasons for positively interacting with a country such as: (a) this country's government is democratic like in the United States; (b) this country believes in equal rights for all people; (c) this country speaks English so I can communicate with the people; (d) the standards of living of this county are similar to those in the United States.

Responses as to why participants may not wish to interact with a specific country also vary. Examples of frequently cited participant responses "against" interacting with a country include: (a) the people practice religions that are very different than mine; (b) these people are lazy and do not work hard. In the United States we value speed and hard work; (c) men are viewed to be superior to women. I believe that women and men should be treated equally; (d) this country is always at war. I believe in peace; (e) children work in sweatshops which is not acceptable; and (f) these people are barbarians and have no respect for people's lives. It is also worthwhile noting that some participants may not want to interact with any countries outside of the United States at all.

Debrief the activity, starting with the comment and question: "All of you have just provided various reasons as to why you may or may not wish to interact with a particular country. What comes to mind after hearing the various responses of your colleagues?" Participant responses will differ, however responses often include statements such as: (a) participants gave good reasons for wanting to interact or not interact with a country; (b) participant responses are based on personal beliefs which may not reflect the beliefs of the rest of the class; and (c) many people compared a country to that of their home country in some way. Note: If participants do not raise the above points, the instructor should raise these topics for discussion. Instructors should also validate each of the participant responses provided as there is no "right" or "wrong" answer to these questions.

Activity 3. Indicate that the prior activity demonstrates the concept of ethnocentrism. Define the term ethnocentrism, utilizing the information shared in the Introduction section of this paper. As part of this introduction, emphasize Sumner's description of ethnocentrism (noted above) and the fact that many people judge other countries and groups of people based on the values and standards of their own culture and/or group. Describe how ethnocentrism can impact business activities and how ethnocentrism can negatively influence a participant's success in business (using the examples described above in this paper or other examples identified by the instructor).

Activity 4. Deliver a short overview on the various psychological reasons that people may be ethnocentric. (This lecture is not to infer that most people have deep seated reasons for ethnocentric tendencies. Instead, the information 
is provided as general background of the topic. Furthermore, examples of each psychological theory are provided in order to help participants better understand the theories and their applications. For example, in addition to the Holocaust example noted above, there are many other historical illustrations of the psychological theories such as the conflict between Catholics and Protestants in Ireland, the Rwandan Genocide and African Slavery.)

Also, note that the primary emphasize of the overview is to focus on Barger's point (2008) that ethnocentrism can be defined as "making false assumptions about others' ways based on one's own limited experience." (Read Barger's statement noted under section 2.1 above.) Then relate that as a result, when people consider different customs and lifestyles of other groups, they often view the other group as abnormal. In actuality, we are all ethnocentric in some shape or form as each of us unconsciously and usually unfavorably compare other groups to our own group based on our personal frames of reference.

Activity 5. Ask participants to take out an $81 / 2$ " by 11 " letter size paper and roll it up lengthwise like a tube. Advise participants to look through the rolled up piece of paper, and write down what they see through this make-shift lens. When asked what they see through the tube, participants often indicate that they see the head of the person in front of them or the back of someone's shirt. Ask: "Were you able to see anything beyond what you just saw through the tube?" In most cases, the answer will be "no." Indicate that looking through the tube provides a limited frame of reference for you to see the world. Reinforce that participants were not able to see beyond their immediate frame of reference which can distort their understanding of a situation. Relate that ethnocentrism works in a similar way. When it comes to cultures and a group's behavior, people see the world through their own limited frames of reference and this limited focus can distort the person's view of what is really going on. This distortion can lead a person to identify incorrect information which can lead to the creation of poor group impressions, bad decision-making, etc. Therefore, ethnocentrism could potentially lead participants to make bad decisions in their personal lives and/or at work. Alternatively, ethnocentrism can yield positive results. When people look beyond their frames of reference and maximize the differences between groups for success, favorable outcomes may result.

Activity 6. An exercise (for credit in classrooms) is assigned so that participants can further explore the potential for ethnocentrism in the real world. For the next session, participants are asked to discuss a 2-5 minute example of a situation involving ethnocentrism which results in either negative or positive outcomes. The example can be a situation that a participant has personally observed or participated in, something written in literature, a situation described in the media, etc. As part of this process, a participant can present a video or movie clip to visually demonstrate ethnocentric behaviors. (The instructor should present some examples of ethnocentrism to demonstrate what an acceptable presentation would look like. Appendix B provides a list of movie clips that were well received in some of my prior sessions. The instructor may wish to infuse some of these clips into the current discussions, as illustrations.) Also, remind participants that the examples discussed should be appropriate for presentation in a class (or business setting).

When the session reconvenes, the instructor first presents an example of an ethnocentric situation that he or she has personally experienced as a way to reinforce the point that everyone can get "pulled into" or create ethnocentric situations at some point in time...even the instructor. Afterwards, each participant presents his or her own example, which no doubt provides plenty of opportunities for interesting discussions. Many "aha" moments occur as participants listen or watch the various ethnocentric presentations. Although participant reactions to the scenarios presented are diverse, on many occasions, I saw participants blushing, and/or laughing as some of these examples "hit home." These examples helped participants recognize that ethnocentric actions are common and can happen to anyone...even themselves. Occasionally, a participant may appear a bit uncomfortable when hearing or watching a presentation. Sometimes these situations create opportunities for discussion. Other times, due to the sensitivity of a topic presented, it is best to instead reinforce the importance of exploring other groups for greater understanding, i.e., to put yourself in the other group's shoes so-to-speak in order to appreciate their culture. Furthermore, cultures are unique and opinions should not be formed about a group based on one representative example of a group's culture.

Activity 7. Each student completes a research and reflection paper that further explores and recaps ethnocentrism as it relates to business. Review the Instructions for this paper (Appendix C1) with the participants and discuss grading guidelines for credit.

After the papers are graded, debrief the activity with a round-robin activity. Going around the room, each participant shares one research example identified within their paper that describes a positive or negative consequence of ethnocentrism on business.

Activity 8. Interestingly, in the first course that completed the Ethnocentrism Exercise participants enthusiastically suggested that they recap key learning points of the Exercise as a tool for future use. This add-on collaborative effort 
was extremely beneficial and meaningful to participants. Together students identified and debated key points of the Exercise which ultimately reinforced an even deeper understanding of the topic. (Appendix D highlights a list of the points provided by the participants who first participated in this activity. The activity was so successful that it is now included in all courses where the Ethnocentric Exercise is delivered.) Whether one agrees with the list provided by the participants (Appendix D) or not is probably less important than the stimulating discussions that resulted as participants prepared this list together.

\section{Introducing the Ethnocentrism Exercise for Business Practitioners}

The implementation of the Ethnocentrism Exercise in business settings would vary, depending upon organizational needs, the time allowed for training, and scheduling issues.

Table 2. Overview of the Exercise Activities 1-6 for Organizations

\begin{tabular}{clc}
\hline Activity & Topic & Appendix \\
\hline 1 & Globalization of Industry Trend & \\
2 & Define Ethnocentrism & \\
3 & Psychology of Ethnocentrism & \\
4 & The Ethnocentric Lens & \\
5 & Assignment: Ethnocentric Movie Clips & B \\
6 & Ethnocentrism Recap: Top 25 Points - Practitioner Developed & D
\end{tabular}

As shown in Table 2, only six of the Exercise's eight steps were typically delivered for organizations (Activity 2 Assess the Country and Activity 7- the Reflection Paper were eliminated.)

Due to specific organizational and/or department mission(s) or goal(s), business practitioners may need to interact with people from specific countries. Therefore, the above-noted activities were geared to address issues related to interacting with people from these countries, as needed.

The author has also facilitated excerpts of the Exercise in sessions as part of a broader conference or training program. When the delivery of Exercise excerpts in separate sessions is required, recommended program delivery is either a two-session process (Session 1: Activities 1-4 and Session 2: Activities 5 and 6) or a three-session process (Session 1: Activities 1-2; Session 2: Activities 3 and 4, and Session 3: Activities 5 and 6.

\section{Exercise Variations for Distance Learning, Hybrid or Online Business Settings}

This Exercise was originally designed for application in a ground course. However, the Exercise is easily modified to work well in hybrid, distance learning or online educational or training programs for organizations. In an online learning environment, activities are posted on electronic learning systems that are supported by the school or business. The author typically uses Discussion Forums to facilitate discussions on various topics. The short topical lectures are delivered via various software packages such as Tegrity or Screencastomatic.) Blogs and/or Wikis are used to display examples of ethnocentrism (allowing participants to post links, video clips, etc.) and to recap key points on ethnocentrism (Activity 8). Blogs and/or Wikis are also available to provide participants with space to accumulate articles, links, and other items related to ethnocentrism which supplements the course work.

The research and reflection paper (Activity 7) may be completed as an individual paper or as an ePortfolio presentation, as determined by the instructor. (An e-portfolio, also known as an electronic portfolio or digital portfolio, is an electronic venue to present participant work, accomplishments, and/or other credentials that a participate posts on a website. These electronic portfolios are frequently utilized for course reflection and/or presentation purposes.) An overview of instructions for an ePortfolio presentation project is shown in Appendix C2 as a convenience to instructors wishing to use an ePortfolio format. If an ePortfolio format is selected, it is recommended that the instructor provides a template for participants to complete as part of the ePortfolio assignment. The instructor should also provide participants with grading guidelines for the ePortfolio project.

\section{Student and Business Practitioner Reflections}

Student Reflections. Student comments about the Ethnocentrism Exercise, as noted within student Reflection Papers (Activity 8), suggest that students were overwhelmingly pleased with the Exercise experience. Table 2 presents a representative sample of student feedback on the Paper's reflection questions. 
Table 3. Sample of Student Responses to the Paper's Reflection Questions

Question

What did you know about ethnocentrism before this semester?

To what extent did the Exercise help you to recognize ethnocentrism in yourself or others?

To what extent did the Exercise enhance your inter-cultural sensitivity?

To what extent did the Exercise enhance your global awareness?

In your opinion, how can this Exercise be improved?

Do you believe that our students about ethnocentrism? Why or why not?

\author{
Sample Student Responses
}

I knew it had to do with people wanting to be with people like themselves.

Nothing.

I heard the word before, but didn't know what it meant.

It was mentioned in one of my textbooks or on a blog.

I didn't think I was ethnocentric. Now I see that we all are.

I now know things to look for to figure out if I'm being ethnocentric or if someone else is.

I still want to stay with my own group, but now I know how to help my my group interact with other groups.

The exercise was helpful because it explained why ethnocentrism happens.

My family is really ethnocentric. I'm showing them this material.

I really liked the class presentations on ethnocentrism.

I didn't realize that ethnocentrism happens in so many areas of life.

I enjoyed putting the recap list together with the class. This list of key points will be very helpful in business.

This exercise helped me to think about how I judge others before getting to know them.

I didn't realize that I compared other groups to my group.

I learned that I have to do my homework on other groups before I communicate with them or I'll blow my chances of building a good working relationship with them.

This exercise changed my behavior toward people that are different than me.

I see that I can actually do something to help people get along better.

Globalization is spreading and you've got to be aware of how it impacts business if you want to be successful at work.

Workforce demographics are changing in companies. You have to be able to work with lots of different types of people.

I live in a neighborhood filled with my ethnic group. I really need to learn more about other people outside my group.

It's a touchy topic. Maybe prepare students more on the topic before jumping into it.

More help in handling situations when people are being ethnocentric.

I think more college classes should give real world exercises like this Students need to know what really happens in business.

Yes. The world is changing and we're always going should school teach to be working with people who are different.

This is important for students to learn who want to work overseas or in companies where globalization is important.

Companies are encouraging employees to work cooperatively. The use of teamwork is spreading within organizations. Ethnocentrism can negatively impact cooperation and teamwork activities.

Technological advances will continue to connect us with people outside of our own areas so we must learn what stops us from working well with others. 
Business Practitioner Reflections. Interestingly, the reflections of business practitioners were, in many cases, not very different from the thoughts conveyed by students. Various business practitioners shared they had not known a great deal about ethnocentrism and did not give the topic of ethnocentrism great thought in their business dealings. Many participants indicated that the topic "ethnocentrism" would now be a more prominent issue in their business activities. I would often use this reflection period as a springboard to discuss specific issues relative to the countries where the participants conducted business. Discussions on these country-specific issues helped to validate the value of participating in training sessions on ethnocentrism as often participants could immediately apply some of the discussion ideas and points to their current jobs.

\section{Discussion and Conclusion}

\section{"Give light and people will find the way." Ella Baker, civil right pioneer}

The aim of this paper is to provide a method to help business students and practitioners appreciate the potential for ethnocentrism in themselves and others, increase inter-cultural sensitivity, and advance global awareness. Business students and practitioners are often unfamiliar with the underlying rationale for ethnocentrism and the resulting consequences of ethnocentric behavior in the workplace. By offering students and practitioners the opportunity to spotlight the ethnocentrism topic, instructors and facilitators enhance individual awareness and comprehension of ethnocentric issues in both personal and business settings. Why is this an important goal? As the trend for business globalization continues to expand, the need to understand and address potential ethnocentric issues contributes to the success of business students and practitioners. Consequently, it benefits both students and practitioners to recognize ethnocentric limitations that could hinder individual or organizational performance and/or the positive outcomes that could ensue due to ethnocentric sensitivity.

It is noteworthy that the approach presented in this paper has some limitations. First, ethnocentrism is a delicate topic to discuss. Individuals delivering this material in business or educational settings should be experienced in facilitating discussions of a sensitive nature. Second, delivery of this material is only the starting point of helping individuals appreciate the issues associated with ethnocentrism. Ethnocentrism may take many different forms (i.e., different beliefs, attitudes, behaviors, etc.). Consequently, additional training is suggested to help individuals explore and apply varied approaches to addressing ethnocentrism. Moreover, individuals who regularly interact with particular countries or cultures should gain a more in-depth understanding of those societies through, for example, emersion courses, ongoing visits to the locale, etc. Enhanced training opportunities will help these individuals better secure the detailed knowledge needed to appropriately interact with these specific groups on a steady basis. Third, it is important for educational institutions and businesses to create environments that proactively promote diversity initiatives. Ethnocentrism is just one small component of the broader issue of diversity. Focusing on ethnocentrism alone without addressing other diversity issues, will not instill and reinforce the value of valuing diversity as a whole.

\section{References}

Adorno, T.W., Frenkel-Brunswik, E., Levinson, D.J., \& Sanford, R. N. (1950). The authoritarian personality. New York: Harper \& Row.

Barger, K. (2004). Ethnocentrism. What is it? Why are people ethnocentric? What is the problem? What can we do about it? Retrieved July 12, 2012, from Indiana University, Department of Anthropology Website: http://www.iupui.edu/ anthkb/ethnocen.htm.

Begley, T.M., \& Boyd, D.P. (2003). Why don't they like us Overseas? Organizing U.S. business practices to management culture clash. Organizational Dynamics, 32, 357-371. http://dx.doi:10.1016/j.orgdyn.2003.08.002.

Berkowitz, L. (1972). Frustration, comparisons, and other sources of emotional arousal as contributors to social unrest. Journal of Social Issues, 28, 77-91. http://dx.doi.10.1111/j.1540-4560.1972.tb00005.x

Bizumic, B., Duckitt, J., Popadic, D., Dru, V., \& Krauss, S. (2009). A cross-cultural investigation into a reconceptualization of ethnocentrism. European Journal of Social Psychology, 39, 871-899.

Booth, K. (1979). Strategy and ethnocentrism. London: Croom Helm Ltd.

Brewer, M.B. (1979). In-group bias in the minimal inter-group situation: A cognitive-emotional analysis. Psychological Bulletin, 86, 307-324. http://dx.doi.10.1002/ejsp.589

Bowen, R.W. (2000). Realizing global education: An immodest proposal. Retrieved July 24, 2012 from http://www.jsl.sagepub.com. 
Bush, V.D., \& Bush, A.J. (1998). Preparing students for the international marketplace: Practitioners' perceptions of specific skills and characteristics needed for success. Journal of Teaching in International Business, 10, 1-16. http://dx.doi. 10.1300/J066v10n02_01

Byrne, D. (1971). The attraction paradigm. New York: Academic Press.

Calof, J.L., \& Beamish, P.W. (1994). The right attitude for international success: Executives' attitudes toward foreign cultures, Business Quarterly, 59, 105-110. http://dx.doi. 9410313880

Cunningham, W.A., Nezlek, J.B., \& Banaji, M.R. (2004). Implicit and explicit ethnocentrism: Revisiting the ideologies of prejudice. The Society for Personality and Social Psychology, Inc., 30, 1332-1346. http://dx.10.1177/0146167204264654

Dollard, J., Doob, L., Miller, N., Mowrer, O., \& Sears, R. (1939). Frustration and aggression. New Haven: Yale University Press.

Gerard, H.B., \& Hoyt, M. (1974). Distinctiveness of social categorization and attitude toward in-group members. Journal of Personality and Social Psychology, 29, 836-842.

Grant, E.S., \& Wren, B.M. (1993). Student ethnocentrism: Its relevance to the globalization of marketing education. Marketing Education Review, 3, 10-17.

Grant, P.R., \& Brown, R. (1995). From ethnocentrism to collective protest: Responses to relative deprivation and threats to social identity. Social Psychology Quarterly, 58, 195-212. http://dx.doi.10.2307/2787042

Hanks, T. (Producer), \& Zwick, J. (Director). (2002). My Big Fat Greek Wedding, [Motion picture]. United States: HBO Television, Playtone Productions and SONY Pictures Productions.

LeVine, R.A, \& Campbell, D.T. (1972). Ethnocentrism. New York: John Wiley \& Sons.

Lewis, I.M. (1976). Social anthropology in perspective. United Kingdom: Penguin.

Lighton, L.D. (Producer), \& Cromwell, J. (Director). (1946). Anna and the King of Siam [Motion picture]. United States: Twentieth Century Fox.

Lynn, R. (1976). The sociobiology of nationalism. New Society (July), 11-14.

Mihalyi, L.J. (1984). Ethnocentrism vs. nationalism: Origin and fundamental aspects of a major problem for the future. Homboldt Journal of Social Relations, 12, 95-113. http://www.jstor.org/stable/23262698

Mosher, D.L., \& Scodel, A. (1960). Relationships between ethnocentrism in children and the ethnocentrism and authoritarian rearing practices of their mothers. Child Development, 31, 369-376. http://www.jstor.org/stable/1125910

Mullen, B., Brown, R., \& Smith, C. (1992). In-group bias as a function of salience, relevance, and status: An integration. European Journal of Social Psychology, 22, 103-122. http://dx.doi.10.1002/ejsp.2420220202

Nehrt, L.C. (1993). Business school curriculum and faculty: Historical perspectives and future imperatives. In S. Tamer Cavusgil (Ed.), Internationalizing business education: Meeting the challenge. Michigan: Michigan State UniversityPress.

Ogretir, A.D., \& Ozcelik, S. (2008). The study of ethnocentrism, stereotype and prejudice: Psycho-analytical and psycho-dynamic theories. Journal of Qafqaz University, 236-244. http://dx.doi.42844035.

Otten, S., \& Moskowitz, G.B. (2000). Evidence for implicit evaluative in-group bias: Affect-biased spontaneous trait inference in a minimal group paradigm. Journal of Experimental Social Psychology, 36, 77-79.

Otten, S., \& Wentura, D. (1999). About the impact of automaticity in the minimal group paradigm: Evidence from affective priming tasks. European Journal of Social Psychology, 29, 1049-1071. http://dx.doi.10.1002/(SICI)1099-0992(199912)29:8<1049::AID-EJSP985>3.0.CO;2-Q

Platow, M.J., McClintock, C.G., \& Liebrand, W.G. (1990). Predicting intergroup fairness and in-group bias in the minimal group paradigm. European Journal of Social Psychology, 20, 221-239.

Postman, N. (1995). The end of education. New York: Vintage Books.

Rokeach, M., \& Rothman G. (1965). The principle of belief congruence and the congruity principle as models of cognitive interaction. Psychological Review, 72, 128-142. http://dx.doi.14282671 
Rosado, C., (1994). Understanding cultural relativism in a multicultural world (Or teaching the concept of cultural relativism to ethnocentric students). Retrieved 7/24/12, from http://rosado.net/pdf/Cultural_Relativism.pdf.

Rushton, J.P. (1989). Genetic similarity, human altruism, and group selection. Behavioral and Brain Sciences, 12, 503-559. http://dx.doi.org/10.1017/S0140525X00057320

Schepisi, F., Newmyer, R.F., Maru, H., Ito, T., \& Uehara, H. (Producer), \& Schepisi, F. (Director). (1992). Mr. Baseball [Motion picture]. United States: Universal Pictures.

Schermerhorn, J.R., Jr. (2010). Management (10 ${ }^{\text {th }}$ ed.). Hoboken: John Wiley \& Sons, Inc.

Scott, T. (1998). Thai exchange students' encounters with ethnocentrism. Social Studies, 89, 177-187. http://dx.doi. $10.1080 / 00377999809599848$

Sherif, M., Harvey, D.J., White, B.J., Hood, W.R., \& Sherif, C.W. (1961). Intergroup conflict and cooperation: The robbers' cave experiment. Oklahoma: Institute of Group Relations.

Stouffer, S.A., Suchman, E.A., DeVinney, L.C., Star, S.A., \& Williams, R.M., Jr. (1949). The American soldier: Adjustment during army life (Vol. 1). Princeton: Princeton University Press.

Sumner, W.G. (1906). Folkways: The sociological importance of usages, manners, customers, mores, and morals. New York: Giann and Company.

Tajfel, H., \& Turner, J.C. (1985). The social identity theory of intergroup behavior. In S. Worchel \& W. Austin (Eds.), Psychology of intergroup relations. Illinois: Nelson-Hall.

Templer, K.J. (2010). Personal attributes of expatriate managers, subordinate ethnocentrism, and expatriate success: A host-country perspective. The International Journal of Human Resource Management, 21, 1754-1768. http://dx.doi.10.1080/09585192.2010.500493

Thomas, M., \& Hill, H. (1999). The impact of ethnocentrism on devising and implementing a corporate identity strategy for new international markets. International Marketing Review, 16, 376-390. http://dx.doi.10.1108/02651339910281956

Tomkiewicz, J., Bass, K., \& Gribble, A. (2011). Potential pitfalls of ethnocentrism in a globalizing world. College Student Journal, 45, 369-375. http://dx.doi. 259679620

Twain, Mark. (1896). Personal recollections of Joan of Arc. San Francisco: Ignatius Press.

Van der Dennen, J.M.G. (1986). Ethnocentrism and in-group/out-group differentiation: A review and interpretation of the literature. In V. Reynolds, V. Folder, and I. Vine (Eds.), The Sociobiology of ethnocentrism: Evolutionary dimensions of xenophobia, discrimination, racism, and nationalism. Georgia: University of Georgia Press.

Wiarda, H.J. (1985). Ethnocentrism in foreign policy: Can we understand the third world? Washington, DC: American Enterprise Institute for Public Policy Research.

Wit, A.P., \& Kerr, N.L. (2002). Me versus just us versus us all: Categorization and cooperation in nested social dilemmas. Journal of Personality and Social Psychology, 83, 616-637. http://dx.doi.10.1037/0022-3514.83.3.616

Yuki, M., Maddux, W.W., Brewer, M.B., \& Takemura, K. (2005). Cross-cultural differences in relationships - and group-based trust. Personality and Social Psychology Bulletin, 31, 48-62. http://dx.doi.10.1177/0146167204271305 


\section{Appendix A. Assess the Country*}

1. Read through the series of countries which are listed in column A.

2. If you would like to interact with this country in business, explain why in Column B.

3. If you would not like to interact with this country in business, explain why in Column C.

A

\begin{tabular}{|c|l|l|}
\hline England & & \\
\hline China & & \\
\hline United States & & \\
\hline Kenya & & \\
\hline France & & \\
\hline Pakistan & & \\
\hline India & & \\
\hline Chile & & \\
\hline Russia & & \\
\hline Israel & & \\
\hline
\end{tabular}

*Instructors are encouraged to modify the countries listed to best meet the objectives of their individual courses and participant populations.

\section{Appendix B. Ethnocentric Illustrations - Samples Movie Clips Presented in Prior Sessions}

1. The father in My Big Fat Greek Wedding continuously states that he can trace any word back to Greek origins (an ethnocentric tendency). When his daughter marries outside of her Greek ethnicity, at the wedding, the father relates, "the root of the word Miller [the surname of the non-Greek husband of the bride] comes from a Greek word, millah, meaning apple, so there you go. And our name, Portokalos, [the surname of the Greek bride] comes from the word meaning orange. So today here [at the wedding], we have apples and oranges. We all different now but in the end we're all fruit" (Hanks \& Zwick, 2002). The message is that they are all human beings and as such they should respect each other's people and their differences in the same way each group wants others to respect their own group.

2. In the movie Mr. Baseball, an American baseball player is transferred to a Japanese baseball team. In Japan, the American falls in love with a beautiful Japanese lady, whose father owns the baseball team that the American plays baseball for. The American baseball player does not adjust well to Japanese customs and people. Ethnocentric reactions occur time and time again throughout this move (Schepisi, Newmyer, Maru, Ito, \& Uehara, 1992).

3. The movie Anna and the King of Siam displays the culture clash of the Victorian values of a British governess in the Royal Court of Siam (now Thailand) with the autocratic rule of Siam's King Mongkut (Lighton \& Cromwell, 1946). 


\section{Appendix C1. Research and Reflection Paper \\ Exploring Ethnocentrism}

Introduction: The accelerated globalization of business creates the need for many organizations to extend their business practices to countries outside of the United States and to work with people from other countries within the United States.

Instructions: You are asked to research and reflect upon the term "ethnocentrism" and the ramifications of ethnocentrism relative to business performance.

-The paper should be a minimum of 5 pages in length, excluding references.

-The paper should be written in accordance with APA formatting standards.

-It is helpful to understand how your work will be assessed before you start the project. Please read the Grading Guidelines for this Activity before starting the Project so you can complete the project to your best advantage.

-Address the following items in your paper:

1. Define ethnocentrism. (A minimum of 500 words is required.)

2. Research and summarize five peer-reviewed articles that discuss the negative impact of ethnocentrism on business. Explain how ethnocentrism can hinder business relationships, business operations, etc.

3. Research and summarize five peer-reviewed articles that discuss the positive impact of ethnocentrism on business. Explain how ethnocentrism can improve business relationships, business operations, etc.

4. Reflections. Answer these questions after you complete items 1-3:

(a) What did you know about ethnocentrism before this semester?

(b) To what extent did the Ethnocentrism Exercise help you to recognize ethnocentrism in yourself or others?

(c) To what extent did the Ethnocentrism Exercise enhance your inter-cultural sensitivity?

(d) To what extent did the Ethnocentrism Exercise enhance your global awareness?

(e) In your opinion, how can the Ethnocentrism Exercise be improved?

(f) Do you believe that our school should instruct its students on issues associated with ethnocentrism? Why or why not? 
Grading Guidelines: The following guidelines will be used to evaluate your work.

\section{SUBSTANCE}

COMMENTS:

1. Define ethnocentrism. (500 word count or more is required.)

2. Research and summarize five peer-reviewed articles that discuss the negative impact of ethnocentrism on business. Explain how ethnocentrism can hinder business relationships, business operations, etc.

3. Research and summarize five peer-reviewed articles that discuss the positive impact of ethnocentrism on business. Explain how ethnocentrism can improve business relationships and operations, etc.

4. Reflection:

(a) What did you know about Ethnocentrism before this semester?

(b) To what extent did the Ethnocentrism Exercise help you to recognize ethnocentrism in yourself or others?

(c) To what extent did the Ethnocentrism Exercise enhance your inter-cultural sensitivity?

(d) To what extent did the Ethnocentrism Exercise enhance your global awareness?

(e) In your opinion, how can the Ethnocentrism Exercise be improved?

(f) Do you believe that our school should instruct its students on issues associated with ethnocentrism? Why or why not?

The content is comprehensive.

Major points are stated clearly and are supported by specific details, examples, or analysis.

DEVELOPMENT/ORGANIZATION

The paper has a structure that is clear, logical and easy to follow.

The paper is directed to the appropriate audience.

The conclusion is logical, flows from the body of the paper and reviews major points.

Transitions between sections aid in maintaining the flow of thought.

The tone is appropriate to the content and assignment.

\section{TECHNICALITIES}

The paper was submitted on or before the due date for the assignment.

The paper is a minimum of 5 pages in length.

Five peer-reviewed articles are referenced within the paper regarding the negative impact of ethnocentrism on business.

Five peer-reviewed articles are referenced within the paper regarding the positive impact of ethnocentrism on business.

Citations and references of original works follow APA guidelines. Other basic APA formatting procedures are followed.

The paper is laid out with effective use of headings, font styles, and white space.

Rules of grammar, usage, and punctuation are followed.

Sentences are complete, clear, concise, and varied.

Spelling is correct.

Points Earned:

Additional Instructor Comments: 


\section{Appendix C2. Research and Reflection ePortfolio Project \\ Exploring Ethnocentrism}

Introduction: The accelerated globalization of business is creating the need for many organizations to extend their business practices to countries outside of the United States and to work with people from other countries within the United States.

Instructions: You are asked to research and reflect upon the term "ethnocentrism" and the ramifications of ethnocentrism upon business performance.

- Please complete the following steps, using the template provided within the ePortfolio information on our course site.

- You should present six separate pages for the project, one page for each item described below.

- It is helpful to understand how your work will be assessed before you start the project. Please read the Grading Guidelines before you begin the project so you can complete the project to your best advantage.

- Citations and references of original works should follow APA guidelines.

\section{Items for Completion}

Page 1: Start the assignment by completing a section entitled, “About Me." Here you will share some basic information to introduce yourself.

Page 2: Define ethnocentrism. (A minimum of 500 words is required.)

Page 3: Research and summarize five peer-reviewed articles that discuss the negative impact of ethnocentrism on business. Explain how ethnocentrism can hinder business relationships, business operations, etc. These examples can be displayed in writing or via visual mediums such as video clips, cartoons, etc. However, your explanation of the implications of the ethnocentric events should be described in writing.

Page 4: Research and summarize five peer-reviewed articles that discuss the positive impact of ethnocentrism on business. Explain how ethnocentrism can improve business relationships, business operations, etc. These examples can be displayed in writing or via visual mediums such as video clips, cartoons, etc. However, your explanation of the implications of the ethnocentric events should be described in writing.

Page 5: Reflections. Answer these questions after you complete pages 1-4:

(a) What did you know about ethnocentrism before this semester?

(b) To what extent did the Ethnocentrism Exercise help you to recognize ethnocentrism in yourself or others?

(c) To what extent did the Ethnocentrism Exercise enhance your inter-cultural sensitivity?

(d) To what extent did the Ethnocentrism Exercise enhance your global awareness?

(e) In your opinion, how can the Ethnocentrism Exercise be improved?

(f) Do you believe that our school should instruct its students on issues associated with ethnocentrism? Why or why not?

Page 6: References are provided in APA format. 
Grading Guidelines: The following guidelines will be used to evaluate your work.

\begin{tabular}{|c|c|}
\hline SUBSTANCE & COMMENTS: \\
\hline \multirow{2}{*}{\multicolumn{2}{|c|}{$\begin{array}{l}\text { 1. Introduce yourself in the About Me section of the project. } \\
\text { 2. Define ethnocentrism. ( } 500 \text { word count or more is required.) }\end{array}$}} \\
\hline & \\
\hline \multicolumn{2}{|c|}{$\begin{array}{l}\text { 3. Research and summarize five peer-reviewed articles that discuss the negative impact of } \\
\text { ethnocentrism on business. Explain how ethnocentrism can hinder business relationships, } \\
\text { business operations, etc. }\end{array}$} \\
\hline \multicolumn{2}{|c|}{$\begin{array}{l}\text { 4. Research and summarize five peer-reviewed articles that discuss the positive impact of } \\
\text { ethnocentrism on business. Explain how ethnocentrism can improve business relationships } \\
\text { and operations, etc. }\end{array}$} \\
\hline \multicolumn{2}{|l|}{ 5. Reflection: } \\
\hline \multicolumn{2}{|c|}{ (a) What did you know about ethnocentrism before this semester? } \\
\hline \multicolumn{2}{|c|}{$\begin{array}{l}\text { (b) To what extent did the Ethnocentrism Exercise help you to recognize ethnocentrism in } \\
\text { yourself or others? }\end{array}$} \\
\hline \multicolumn{2}{|c|}{ (c) To what extent did the Ethnocentrism Exercise enhance your inter-cultural sensitivity? } \\
\hline \multicolumn{2}{|c|}{ (d) To what extent did the Ethnocentrism Exercise enhance your global awareness? } \\
\hline \multicolumn{2}{|c|}{ (e) In your opinion, how can the Ethnocentrism Exercise be improved? } \\
\hline \multicolumn{2}{|c|}{$\begin{array}{l}\text { (f) Do you believe that our school should instruct its students on issues associated with } \\
\text { ethnocentrism? Why or why not? }\end{array}$} \\
\hline \multirow{2}{*}{\multicolumn{2}{|c|}{$\begin{array}{l}\text { The content is comprehensive. } \\
\text { Major points are stated clearly }\end{array}$}} \\
\hline & \\
\hline \multicolumn{2}{|c|}{ DEVELOPMENT/ORGANIZATION } \\
\hline \multicolumn{2}{|c|}{ The project has a structure that is clear, logical and easy to follow. } \\
\hline \multirow{2}{*}{\multicolumn{2}{|c|}{$\begin{array}{l}\text { The project is directed to the appropriate audience. } \\
\text { The conclusion is logical, flows from the body of the project and reviews major point }\end{array}$}} \\
\hline & \\
\hline \multicolumn{2}{|c|}{ Transitions between sections aid in maintaining the flow of thought. } \\
\hline \multicolumn{2}{|c|}{ The tone is appropriate to the content and assignment. } \\
\hline \multicolumn{2}{|l|}{ TECHNICALITIES } \\
\hline \multicolumn{2}{|c|}{ The project was submitted on or before the due date for the assignment } \\
\hline \multicolumn{2}{|c|}{ The project is 6 pages, one page for each topic. } \\
\hline \multicolumn{2}{|c|}{$\begin{array}{l}\text { Five peer-reviewed articles are referenced within the project regarding the negative impact } \\
\text { of ethnocentrism on business. }\end{array}$} \\
\hline \multicolumn{2}{|c|}{$\begin{array}{l}\text { Five peer-reviewed articles are referenced within the project regarding the positive impact of } \\
\text { ethnocentrism on business. }\end{array}$} \\
\hline \multicolumn{2}{|c|}{$\begin{array}{l}\text { Citations and references of original works follow APA guidelines. Other basic APA } \\
\text { formatting procedures are followed. }\end{array}$} \\
\hline \multicolumn{2}{|c|}{ The project is laid out with effective use of headings, font styles, and white space. } \\
\hline \multicolumn{2}{|c|}{ Rules of grammar, usage, and punctuation are followed. } \\
\hline \multirow{2}{*}{\multicolumn{2}{|c|}{$\begin{array}{l}\text { Sentences are complete, clear, concise, and varied. } \\
\text { Spelling is correct. }\end{array}$}} \\
\hline & \\
\hline \multicolumn{2}{|l|}{ Points Earned: } \\
\hline Additional Instructor Comments: & \\
\hline
\end{tabular}




\section{Appendix D. Ethnocentrism Recap: Top 25 Points Participant Developed}

- Recognize the potential for ethnocentrism in oneself and others. Acknowledge that everyone is ethnocentric at one point in time.

- Identify one's personal orientation to your own group and learn about one's own group.

- Understand the cultural orientation of your employer.

- Highlight the value of considering different approaches and perspectives recommended by other groups.

- Recognize that a person may have limited knowledge of other groups and may not know when they are misinterpreting or misunderstanding the ways of other groups.

- Do not assume that other groups will recognize the meanings of items or things that are familiar to a student.

- Recognize that ethnocentrism can impact relationships between groups and/or create conflict...by you and/or by the other group.

- Recognize that ethnocentrism can interfere with a person's career success and/or the business success of his or her employer.

- Acknowledge that ethnocentrism can impact decision making activities.

- Do not create a "we" versus "them" situations.

- View interactions with other groups as opportunities to learn new things.

- Express the same degree of respect and confidence in the knowledge and skills of all groups.

- Refrain from making premature judgments or generalizations about other groups' ways.

- Recognize that other groups may or may not be willing to accept or change their ethnocentrism or be open to the ways of your group.

- Identify resources to learn about interacting with other groups of people that you may be working with at work. Possible resources of information are: the Internet, books and articles, speaking with people from the other group, asking questions, joining a group activity that provides opportunities to participate with other groups, media communications about groups, observations of the other group's behaviors, learn the language of other groups, listen to what is truly being said (i.e., the meaning of actions and/or communications, etc.).

- Participate in global educational or business opportunities that help individuals become more knowledgeable about other groups.

- Learn about other groups that you interact with before your interactions take place (e.g. their culture, values, behaviors, interests, communication styles, history of the people, their economy, work ethic and rules, religions, gestures, styles of dress, politics, rules of social etiquette, etc.).

- Consider potential consequences of your actions before interacting with other groups.

- Reassess your methods for interacting with another group so as to potentially include approaches used by the other group.

- Practice the skill of interacting with the other group before interacting with the other group.

- Do not make potentially helpful suggestions based on typecasting as they may be considered patronizing.

- Start your interactions with other groups as small tasks that you believe will be successful so as to make positive first impressions.

- Watch the other group's reactions to your interactions to determine if your actions are well received or not.

- Ask the other group what they think your actions or communications mean in order to help identify if you are both on the "same page."

- Reflect upon your interactions with the other group to identify "what went right" and "what can be improved upon." Consider keeping a journal on interactions. 